\title{
Where the Dimensions of Religion and Mass Media Social Marketing Campaigns Intersect
}

\author{
Patrick van Esch ${ }^{1}$, Tania von der Heidt ${ }^{1}$, Philip Neck ${ }^{1} \&$ Linda Jean van Esch ${ }^{2}$ \\ ${ }^{1}$ Southern Cross Business School, Southern Cross University, Queensland, Australia \\ ${ }^{2}$ Western Australian School of Mines, Faculty of Science \& Engineering, Curtin University, Perth, Australia \\ Correspondence: Patrick van Esch, Southern Cross Business School, Southern Cross University, Locked Mail \\ Bag 4, Coolangatta, QLD 4225, Australia. Tel: 61-7-5589-3043. E-mail: vesch54@hotmail.com
}

Received: November 15, 2014 Accepted: January 20, 2015 Online Published: April 30, 2015

doi:10.5539/ass.v11n12p103 URL: http://dx.doi.org/10.5539/ass.v11n12p103

\begin{abstract}
This paper explores mass media social marketing practitioner insights of where the dimensions of religion and mass media social marketing campaigns intersect. Under an interpretive paradigm (Crotty, 1998), in-depth interviews were conducted with five expert mass media social marketing practitioners in Australia. The data was analysed qualitatively and three themes emerged from the results: (1) The dimensions of religion do have application in mass media social marketing campaigns; (2) participants employed the dimensions of religion with care to avoid a negative effect on the target audience and (3) while social marketing campaigns use 'preaching' as a communication medium, it tends not to be deliberately linked to religious practices.
\end{abstract}

Keywords: dimensions of religion, mass media social marketing campaigns, in-depth interviews, qualitative research, tree map analysis

\section{Introduction}

Founded in an earlier paper (Van Esch, 2013), both the dimensions of religion and mass media social marketing campaigns continue to receive growing attention in the literature. An abstract search of the EBSCO Business Source Premier database for the terms 'dimensions of religion' and 'mass media social marketing campaigns' from 1960 to 2010 shows that literature related to the combination of both concepts is growing steadily, albeit off a low base. The analysis and review of mass media social marketing campaigns is a continuation of the body of work founded in Van Esch et al., (2013) and the analysis of social marketing campaign texts has recently been reported and founded in Van Esch et al., (2014). The data was collected from five expert mass media social marketing practitioners who were identified from government and/or private agencies that specialise in the design, creation and evaluation of mass media social marketing campaigns and who have been directly related to or have experienced the topic under investigation. This paper briefly recaps both parent bodies of literature, identifies gaps and presents the objective of a broader research program. A study related to one part of the program is presented in this paper, which describes the method, presents the results and draws conclusions.

\section{Theoretical Foundations}

\subsection{Mass Media Social Marketing}

Kotler and Zaltman (1971) first coined the term 'social marketing' as a reference to the application of marketing as a solution to social and health problems. French et al., (2010) recognised that the social marketing discipline derives from two distinct movements - marketing and social sciences. Both are concerned with how best to influence people's behaviour. Furthermore, French (2013) was part of a working group who developed an international consensus definition of social marketing:

"Social marketing seeks to develop and integrate marketing concepts with other approaches to influence behaviours that benefit individuals and communities for the greater social good. Social marketing practice is guided by ethical principles. It seeks to integrate research, best practice, theory, audience and partnership insight, to inform the delivery of competition sensitive and segmented social change programmes that are effective, efficient, equitable and sustainable". 
Hornik and Yanovitsk (2003) through the theory of social marketing at the time proposed that behaviour change through a series of linear steps is the outcome of an effective social marketing campaign. A change in behaviour begins with acquiring knowledge about the costs and benefits to perform the desired behaviour; next a change in beliefs is followed by an intention to act. Behavioural intentions eventually translate into actual behaviour. An assumption of the linear model is that individuals receive information passively and make choices freely based on the information provided.

A number of theories relate to social marketing: (1) Theories explaining social persuasion include the elaboration-likelihood model, which holds that attitudes are changed via two routes of persuasion - central and peripheral (Petty \& Cacioppo, 1986). (2) Theories of behaviour change include the theory of reasoned action (Fishbein and Ajzen, 1974), protection motivation theory (Rogers, 1975), health belief model (Rosenstock, 1977), theory of interpersonal behaviour (Triandis, 1977) and theory of planned behaviour (Ajzen, 1985). (3) Theories explaining the process of behaviour change include the theory of self-regulation (Carver and Scheier, 1981) and the trans-theoretical model of change (Prochaska \& DiClemente, 1983).

Social marketing campaign messages can be delivered through multiple channels or activities, which may include mass media (Wundersitz, 2011). Mass media can include audio-visual media (e.g. television, cinema), printed media (e.g. newspapers), interpersonal communication (e.g. lectures) and electronic (e.g. emails, websites) (Delhomme et al., 2009). As a means of promoting attitude and behaviour change to improve public health, mass media campaigns have been used extensively. Campaigns include smoking cessation (McPhee et al., 1995), promoting safer road use (Woolley et al., 2001), health service utilisation (Grillie et al., 2002) and encouraging participation in physical activity (Cavill \& Bauman, 2004). Such mass media campaigns target the population as a whole, with benefits providing social support for behaviour change and the potential altering of attitudes and/or knowledge of a large proportion of the population (Redman et al., 1990).

The mass media social marketing campaigns analysed, reported and founded in Van Esch et al., $(2013 ; 2014)$ are deemed to have evidence of each of Andreasen's (2002) six social marketing benchmarking criteria (Carins \& Rundle-Thiele, 2013). Table 1 summarises the six criteria.

Table 1. Social marketing benchmarking criteria

\begin{tabular}{|c|c|c|}
\hline No. & Criteria & Description \\
\hline 1 & Behaviour change & $\begin{array}{l}\text { The intervention seeks to change behaviour and has specific measurable } \\
\text { behavioural objectives. }\end{array}$ \\
\hline 2 & Consumer research & $\begin{array}{l}\text { Formative research is conducted to identify consumer characteristics and } \\
\text { needs. Interventions are pre-tested with the target group. }\end{array}$ \\
\hline 3 & Segmentation and targeting & $\begin{array}{l}\text { Different segmentation variables are used and a strategy tailored to the } \\
\text { segments. }\end{array}$ \\
\hline 4 & Marketing mix & $\begin{array}{l}\text { The intervention must consist of communications plus at least one other } \\
\text { 'P'. These P's may include Policy or People. }\end{array}$ \\
\hline 5 & Exchange & $\begin{array}{l}\text { The intervention considers what will motivate people to engage } \\
\text { voluntarily with the intervention and offers them something beneficial in } \\
\text { return, whether that is intangible or tangible. }\end{array}$ \\
\hline 6 & Competition & $\begin{array}{l}\text { The intervention considers the appeal of competing behaviours (including } \\
\text { the current behaviour) and uses strategies to decrease competition. }\end{array}$ \\
\hline
\end{tabular}

Source: Andreasen, (2002).

\subsection{The Dimensions of Religion}

Fam, Waller and Erdogan (2002) continue to argue that "In a constantly changing and increasingly globalized world, religion still plays a significant role in influencing consumer behaviour". Religious beliefs play a significant part in sculpting social behaviour with $74 \%$ of Australia's population reported having a religious affiliation (ABS, 2004; 2006), 77\% of Britain's population reported belonging to a religion (ONS, 2001) whilst $79.9 \%$ of America's population indicated they had a religious identification (Kosmin \& Keysar, 2008). According to Hirschman (1983), religious affiliations help shape attitudes towards dancing, magazines, restaurants, political ideas and tend to influence the way people live, the choices they make, what they eat and whom they associate with. While the content of such religious beliefs and affiliations may vary from one religion to another, their constructs and underlying themes may be conceptualised using the seven dimensions of religion (Smart, 1996). Table 2 summarises the dimensions of religion and its identifiers. 
Table 2. Dimensions of religion and their identifiers

\begin{tabular}{|c|c|}
\hline Dimension & Identifiers \\
\hline $\begin{array}{l}\text { Practical and } \\
\text { ritual }\end{array}$ & $\begin{array}{l}\text { Practices and rituals of different traditions and cultures, preaching, prayers, ceremonies, } \\
\text { meditation, worship, spiritual awareness, ethical insight, communities re-enacting their myths } \\
\text { and stories to confirm and express beliefs through action. }\end{array}$ \\
\hline $\begin{array}{l}\text { Experiential } \\
\text { and } \\
\text { emotional }\end{array}$ & $\begin{array}{l}\text { Evoking religious feelings, direct experiences of the divine, visions, enlightenment, security, } \\
\text { comfort, awe, inexplicable presence, mystery, ecstasy, dread, guilt, awe, devotion, liberation, } \\
\text { inner peace, bliss, assurance of salvation, brilliant emptiness, an expanded sense of identity, } \\
\text { accumulation of religious knowledge and experiences and unconscious, super-conscious and/or } \\
\text { neurologically induced events of a higher reality. }\end{array}$ \\
\hline $\begin{array}{l}\text { Narr } \\
\text { myth }\end{array}$ & $\begin{array}{l}\text { Myths or sacred stories, systematic or complete interpretation of god(s), the nature of humans } \\
\text { and their place in the universe, historical accounts, hagiography, oral traditions, authority from } \\
\text { the divine. }\end{array}$ \\
\hline $\begin{array}{l}\text { Doctrinal and } \\
\text { philosophical }\end{array}$ & $\begin{array}{l}\text { Doctrines, systematic formulation of religious teachings and beliefs, sacred texts, the nature of } \\
\text { divinity, ultimate reality, the relationship of humans to an ultimate, real, divinity. Religious } \\
\text { narrate, reflection, structured beliefs beyond the symbolic aspect of myths, faith, and values of a } \\
\text { tradition, worldly views and salvation. }\end{array}$ \\
\hline $\begin{array}{l}\text { Ethical and } \\
\text { legal }\end{array}$ & $\begin{array}{l}\text { Laws, rules, guidelines or behavioural precepts for conduct according to which the community, } \\
\text { employees, employers, consumers, producers and citizens at every level of existence judge a } \\
\text { person, conformity, a supernatural realm and higher being of a particular faith. }\end{array}$ \\
\hline $\begin{array}{l}\text { Socic } \\
\text { instit }\end{array}$ & $\begin{array}{l}\text { Tradition, belief system, social organisation, shared and implied attitudes practiced by } \\
\text { individuals or the group, community membership, participation in public, exemplary } \\
\text { individuals, buildings, works of art, cities, symbols, idols, other creations and places of worship, } \\
\text { formally organised, a sense of normative values, group bonding, functioning society and a } \\
\text { community to live in. }\end{array}$ \\
\hline The $\mathrm{m}$ & $\begin{array}{l}\text { Ordinary objects or places that symbolise or manifest in material form that help connect the } \\
\text { believer to the sacred, supernatural or the divine, religious artefacts, religious capital, sacred } \\
\text { objects, sacred tourism, pilgrimage and sacred areas and/or places. }\end{array}$ \\
\hline
\end{tabular}

Source: Adapted from Smart, (1996).

\subsection{The Intersect between Social Marketing and Religion}

The possible link between mass media social marketing campaigns and the dimensions of religion merits investigation, as this could be one technique to reach people (a targeted social audience) on a large scale. While a substantial body of work is available for both concepts, there is limited, literature on this intersect. Hence, it is unclear whether and how the dimensions of religion are used in mass media social marketing campaigns. We are also unsure if social marketing practitioners can identify and accept the link between the dimensions of religion and social marketing and their willingness to apply the dimensions of religion to mass media social marketing campaigns. Given these gaps in knowledge, the objective of the research program was to explore through in-depth interviews with social marketing practitioners the use of the dimensions of religion. This paper reports on the research question: Do the seven dimensions of religion have application in mass media social marketing campaigns?

\section{Methodology}

\subsection{An Interpretive Approach}

The two central paradigms in social science research are known as the positivist and the interpretive approaches (Perry, 1995, p. 22; Veal, 2005, p. 24). The exploratory nature of the stated research objective fits with the intentions, philosophy and strategies of the interpretive research paradigm and is based on the epistemology of idealism.

Higgs (2001) defines idealism as "a social construction encompassing a number of research approaches, which have a central goal of seeking to interpret the social world". Crotty (1998) suggests that within the interpretive paradigm, human beings construct meanings in unique ways, which are dependent on context, experiences and frames of reference of the world they are trying to interpret. With this type of research, Creswell (1998) suggests that as findings emerge due to the interactions between the researcher and the participants (i.e. social marketing practitioners); the research also progresses because subjectivity is valued (Bhattacherjee, 2012). This 
acknowledges that the research participants are human and incapable of total objectivity because their reality is constructed by subjective experiences within certain situations. Therefore, the values held by the researcher, the questions asked of the participants and the generated and interpreted findings all allow the research to be value-bound. Sense making, rather than explaining or predicting, must be the emphasis in order to understand the experience. For researchers using qualitative analysis, it is imperative to have a creative, ethical investigative and participant-in-context attitude (Miles \& Huberman, 1984).

Given its potential to generate new understandings of the emerging religion in social marketing concept and to obtain practical knowledge that is embedded in the world of human interaction and meanings, the interpretive paradigm was deemed the most suitable for this research and is informed by the work of Denzin and Lincoln $(1994 ; 2000)$. Particular advantages of qualitative research include (1) a humanistic and inherently literary focus, which generally starts from and returns to words (Denzin \& Lincoln, 2000); (2) provides robust insights from actions that have occurred in a real-life context and preserves the intended meaning which forms an understanding of underlying social processes and meaning in a business/management environment (Van Mannen, 1998).

\subsection{In-depth Interviews Technique}

In-depth interviews were used as a qualitative research technique, to conduct individual interviews to explore experiences, ideas, opinions, perspectives, thoughts and views of five informed experts possessing knowledge of mass media social marketing campaigns and the dimensions of religion. Under the principle of saturation, Jette, Grover and Kech (2003) argue that expertise in a chosen topic can reduce the number of participants needed in a study. In support of the relatively small sample size, Van Esch and Van Esch, (2013) argue that "in qualitative research studies, there are numerous factors that can determine a sample size and the literature is limited as to what a sufficient sample size is (Mason, 2010)". Whilst Guest, Bunce and Johnson (2006: 59) argue that "there is little practical guidance for estimating sample sizes for robust research prior to data collection". Therefore, in a review of the literature, seven (7) sources provide practical guidelines for sample sizes (Table 3).

Table 3. Type of research and sample size

\begin{tabular}{lll}
\hline Source & Type of research & Sample size \\
\hline Creswell (1998: 64); Morse (1994: 225) & Qualitative research & 5 to 25 \\
Bertaux (1981: 35) adapted from (Guest et al., 2006) & Qualitative research & $\begin{array}{l}15 \text { is the smallest } \\
\text { acceptable sample }\end{array}$ \\
Charmaz (2006: 114) & Qualitative research & $\begin{array}{l}25 \text { is adequate for } \\
\text { smaller projects }\end{array}$ \\
Ritchie et al., (2003: 84) & Qualitative research & $<50$ \\
Van Esch and Van Esch (2013: 228-229) & Qualitative Research & 5 \\
\hline
\end{tabular}

Source: Adapted from Mason (2010); Van Esch and Van Esch (2013).

The sample target identified was mass media social marketing practitioners in Australia that were identified from government and/or private agencies who specialise in the design, creation and evaluation of mass media social marketing campaigns.

Therefore, to bolster the analysis and findings of the textual analysis founded in Van Esch et al., (2014), and to further distil any emerging themes from the data in order to draw meaningful conclusions, the in-depth interviews consisted of eight questions (Table 4).

Table 4. In-depth interview questions

$\begin{array}{ll}\text { Question } 1 & \text { Do the dimensions of religion have application in mass media social marketing campaigns? } \\ \text { Question } 2 & \text { The campaigns often use a preaching context; do you think this is related to religious practices? } \\ \text { Question } 3 & \text { Is a preaching context an appropriate driver for mass voluntary behaviour change? } \\ \text { Question } 4 & \begin{array}{l}\text { Some campaigns utilise a theme of Assurance of Salvation without using explicit religious language; } \\ \text { do you think the campaign would benefit or suffer from the use of religious language? }\end{array} \\ \text { Question } 5 & \text { Is an Assurance of Salvation theme an appropriate driver for mass voluntary behaviour change? } \\ \text { Question } 6 & \text { Whilst five of the seven dimensions were evident, many of the identifiers were not; would the }\end{array}$


increased use of the identifiers in an implicit and/or explicit way reinforce a campaign message?

Question 7 Two dimensions that are explicit in religious content were not evident in the campaigns; would this represent a deliberate extent to mitigate the use of religion in mass media social marketing campaigns?

Question 8 The two non-evident dimensions: The Material and Narrative or Mythic, do they or their identifiers have application within mass media social marketing campaigns?

Source: Van Esch et al., (2014).

Therefore, intentionally using more than one method of analysing data, the in-depth interviews were used to synthesise the data (Reiman, 1979); this approach allowed the individual methods to complement each other and the comparison used to triangulate the findings and add validity in drawing meaningful implications and conclusions. The in-depth interviews for this study were conducted one-on-one and either face-to-face or face-to-face through an electronic medium (e.g. Skype). In terms of formality and structure, each interview was flexible in its approach. This meant that an in-formal approach was adopted in the delivery. During the interview, questions were either omitted or used in a different order dependent on the direction of the dialogue; probes were at the discretion of the interviewer; the interviewer answered questions and made clarifications; the style of language was adjusted when necessary and the wording of questions was flexible. The data collected was rich, due to the high level of personal interest and response to the research from the interviewees. Even though the topics were covered in different orders and in different ways during the different interviews, this allowed each interview to become a story in its own right. The unique nature and structure of each story was of significant interest, as they were used to guide the research propositions. The interviews were recorded with participant consent. This allowed for the ability to produce complete verbatim transcripts of interviews.

\section{Results and Discussion}

\subsection{Interview Results and Discussion}

A qualitative analysis of the participants' responses indicates that the dimensions of religion do have application in mass media social marketing campaigns. However, as demonstrated in the following quotes, participants appear to be committed to specific dimensions, rather than to the full suite of the seven dimensions of religion:

"Yes, specifically symbols or myths that are used as subliminal stimuli portraying an experience that can influence the betterment of the campaigns target audience" (Participant 1). "Yes, provided that it is in context within today's reality. The campaigns that use preaching generally are connected to a patriarchal figure (Participant 2). "Rituals and especially the social and institutional aspect; which are very important factors when planning campaigns. Not only are religious themes important but more so their integration with technology and how that links with the audience" (Participant 4). "The 'doctrinal and philosophical' and especially the 'practical and ritual' dimensions are expected in campaigns. The Narrative or mythic assists with campaigns focused on driving social responsibility on a broader scale” (Participant 5).

Further, as indicated in the following quotes, participants expressed hesitation or caution to the use of certain dimensions of religion to ensure that there was not a negative effect on the target audience:

"The campaigns that use preaching generally are connected to a patriarchal figure. This may have a good influence on some people, but; this is only one sided. On the other side, the context of messages or visualisation of the patriarch may anger some audience members. Therefore, plenty of consideration must be given to such a dynamic during the planning phase of the campaign" (Participant 2). "It is a balance because too much emphasis incorporating religious vocabulary or religious direction may damage the campaign message and ultimately anger or put the target audience offside" (Participant 5). "From a modern view, it is very sensitive. They would need to be very flexible and be able to fit with the different non-religious values that people align to. I think that they should never be used within a campaign to bring about a bad reaction in people or cause aggression, as this would be detrimental to the success of the campaign and potentially to a society that is united by religion" (Participant 3 ).

When asked if a preaching context in social marketing campaigns was related to religious practices, the respondents indicated that this was not so. As suggested in the following key quotes', 'preaching' is not considered as a campaign communication technique; rather the focus is on the call to action which can be achieved through different mediums:

I think it may also be seen as lecturing but I can't say that the success of the campaign depends on a preaching context. In terms of marketing, a preaching context is not necessarily or deliberately linked to any religious 
practices" (Participant 1). "Preaching can incite some kind of fears in the human psyche. The preaching may use an apathetical vocabulary and therefore I don't think that this is related to religious practices. If it is, I think it must be a coincidence" (Participant 2). "It may be some kind of call to action but for me it's not preaching" (Participant 3). "In general there is some kind of calling, but I don't know how much it can be attributed to preaching. Maybe theoretically it has religious dependence" (Participant 4). "Preaching may be used as a call to action when you are explaining what is good and what is not. When using preaching in social marketing, the characteristics of the dimensions of religion may instil loyalty towards the desired behaviour change over time; this would need to be tested" (Participant 5).

\subsection{Tree Map Analysis}

The verbatim interview transcripts were coded against the seven dimensions of religion and their identifiers using a qualitative software tool (e.g. NVivo) and subjected to a tree map analysis to highlight hierarchical data and to compare nodes based on their attribute values (Table 5).

Five of the seven dimensions of religion appear in the tree map analysis. The results from the tree map analysis indicate the dimension's significance and that of the identifiers within it. The most significant dimensions and identifiers are (1) Social and institutional (exemplary individuals, participation in public, group bonding and community membership); (2) Practical and ritual (preaching, ceremonies, re-enactment of myths and stories and ethical insight) and (3) Doctrinal and philosophical (religious narrative). Dimensions and identifiers of medium significance are (1) Experiential and emotional (assurance of salvation, evoking religious feelings and comfort); (2) Ethical and legal (guidelines, rules and judgement of a person). The Material (religious artefacts) was a low ranking dimension. The final dimensions, which did not appear in the results - Narrative and mythic - appears to be of lowest significance.

Table 5. Tree map analysis for all interviews

\begin{tabular}{|c|c|c|}
\hline Dimension $\mid$ Identifier & Coding references & Items coded \\
\hline Social and Institutional|Exemplary individuals & 48 & 19 \\
\hline Practical and Ritual $\backslash$ Preaching & 45 & 19 \\
\hline Doctrinal and Philosophical Religious narrative & 41 & 16 \\
\hline Experiential and Emotional\Assurance of salvation & 33 & 17 \\
\hline Practical and Ritual $\backslash$ Ceremonies & 21 & 9 \\
\hline Experiential and EmotionallEvoking religious feelings & 16 & 4 \\
\hline Experiential and Emotional $\backslash$ Comfort & 13 & 7 \\
\hline Ethical and Legal $\backslash$ Guidelines & 7 & 5 \\
\hline Social and Institutional $\backslash$ Participation in public & 6 & 4 \\
\hline Social and Institutional $\backslash$ Group bonding & 5 & 1 \\
\hline Social and Institutional $\backslash$ Community membership & 5 & 2 \\
\hline Practical and Ritual $\backslash$ Re-enactment of myths and stories & 4 & 2 \\
\hline Ethical and Legal \Rules & 4 & 3 \\
\hline Doctrinal and Philosophical Symbolic aspect of myths & 4 & 4 \\
\hline 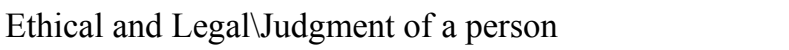 & 4 & 4 \\
\hline Practical and RituallEthical insight & 3 & 2 \\
\hline The Material\Religious artefacts & 2 & 1 \\
\hline
\end{tabular}

Source: Van Esch et al., (2014).

\subsection{Key Themes Emerging from the Results}

Table 6 below summarises the emergent themes and contribution to knowledge that has been achieved as a result of a comparison of the results from both the in-depth interviews and the qualitative analysis from this research (Van Esch et al., 2014). The following approach has been adopted in classifying the contribution to knowledge of this research:

- If a research output did not have a counterpart in the existing literature, it is classified as 'advance to current knowledge'

- If there was a similarity with the existing literature, the research output has been classified as 'addition to current knowledge' 
- If there was a direct link with the existing literature, the research output has been classified as 'confirmation of current knowledge'.

Table 6. Summary of contribution to knowledge

\begin{tabular}{ll}
\hline Output & Contribution \\
\hline $\begin{array}{l}\text { The dimensions of religion do have application in mass media social } \\
\text { marketing campaigns }\end{array}$ & Advance to current knowledge \\
$\begin{array}{l}\text { While social marketing campaigns use 'preaching' as a communication } \\
\text { medium, it tends not to be deliberately linked to religious practices }\end{array}$ & Addition to current knowledge \\
$\begin{array}{l}\text { Participants employed the dimensions of religion with care to avoid a } \\
\text { negative effect on the target audience }\end{array}$ & Confirmation of current knowledge \\
\hline
\end{tabular}

Source: Developed for this research.

\section{Conclusion}

This research explored five practitioners' views on where the dimensions of religion and mass media social marketing campaigns intersect. Several key themes emerge from the results. Firstly, the dimensions of religion do have application in mass media social marketing campaigns and the three most significant dimensions are social and institutional, practical and ritual and doctrinal and philosophical. This theme contributes to an advance in current knowledge. Secondly, participants employed the dimensions of religion with care to avoid a negative effect on the target audience. This is a deliberate intent to mitigate the use of religion in mass media social marketing campaigns. Hence, explicit religion or religious application within a social marketing campaign is considered risky by practitioners. This theme contributes to an addition in current knowledge. Thirdly, while social marketing campaigns use 'preaching', it tends not to be deliberately linked to religious practices. This theme confirms current knowledge. As with most research, this study is limited in a number of ways. In particular, the sample of expert mass media social marketing campaign practitioners is relatively small. This means that the emerging findings from the qualitative analysis require further exploration and validation. In future research the scale of this study might be expanded to more recent social marketing campaigns and, where possible, replicated a number of times before any further implications and conclusions can be made (Remenyi et al., 1998, p. 36).

\section{References}

Ajzen, I. (1985). From intentions to action: A theory of planned behavior. In J. Kuhl, \& J. Beckman (Eds.), Action-control: From cognition to behavior. Heidelberg: Springer.

Andreasen, A. R. (2002). Marketing social marketing in the social change marketplace. Journal of Public Policy Marketing, 21, 3-13.

Australian Bureau of Statistics (ABS). (2004). Religious affiliation and activity. Catalogue Number 4102.0 Australian Social Trends. Canberra.

Australian Bureau of Statistics (ABS). (2006). Religious Affiliation, Catalogue Number 1301.0. Year Book Australia, Canberra.

Bhattacherjee, A. (2012). Social Science Research: Principles, Methods and Practices, USF Tampa Bay Open Access Textbooks Collection, Book 3. Retrieved June 28, 2013 from http://scholarcommons.usf.edu/ oa_textbooks $/ 3$

Carins, J. E., \& Rundle-Thiele, S. R. (2013). Eating for the better: a social marketing review (2000-2012). Public Health Nutrition, 1-12. http://dx.doi.org/10.1017.S1368980013001365.

Carver, C. S., \& Scheier, M. F. (1981). Attention and self-regulation: A control-therapy approach to human behaviour. New York: Springer-Verlag.

Cavill, N., \& Bauman A. (2004). Changing the way people think about health-enhancing physical activity: Do mass media campaigns have a role? Journal of Sports Science, 22(8), 771-790.

Creswell, J. W. (1998). Qualitative Inquiry and Research Design: Choosing among five traditions. Thousand Oaks CA, Sage Publications, Inc.

Crotty, M. (1998). The foundations of social research: Meaning and perspective in the research process. Sydney, New South Wales, Australia: Allen and Unwin. 
Delhomme, P., De Dobbeleer, W., Forward, S., \& Simoes, A. (2009). Manual for designing, implementing and evaluating road safety communication campaigns. Brussels: Belgian Road Safety Institute.

Denzin, N. K., \& Lincoln, Y. (2000). Qualitative research. Thousand Oaks, USA.

Denzin, N. K., \& Lincoln, Y. S. (1994). Handbook of qualitative research (pp. 361-376). Thousand Oaks, CA, US: Sage Publications.

Fishbein, M., \& Ajzen, I. (1975). Belief, attitude, intention and behaviour: An introduction to theory and research. Reading, MA: Addison-Wesley.

French, J. (2013). Developing the international consensus definition of Social Marketing. Viewpoint, Australian Association of Social Marketing, 2(5). Retrieved November 9, 2014, from http://www.aasm.org.au/wpcontent/uploads/2013/07/AASM-Viewpoint-Vol-2-Issue-5-Professor-Jeff-French-Developing-the-internatio nal-consensus-definition-of-social-marketing.pdf

French, J., Blair-Stevens, C., Merritt, R., \& McVey, D. (2010). Social Marketing and Public Health: Theory and Practice. Oxford: Oxford University Press.

Grilli, R., Ramsay, C., \& Minozzi, S. (2002). Mass media interventions: effects on health services utilisation. Cochrane Database of Systematic Reviews, 1. http://dx.doi.org/10.1002/14651858.CD000389

Hornik, R., \& Yanovitzky, I. (2003). Using theory to design evaluations of communication campaigns: The case of the national use anti-drug media campaign. Communication Theory, 13(2), 204-224.

House, H. W. (2006). Charts of world religions. Zondervan.

Kosmin, B. A., \& Keysar, A. (2008). American Religious Identification Survey, Summary Report, Trinity College Hartford Connecticut. Retrieved April 11, 2010, from http://www.americanreligionsurvey-aris.org/reports/ ARIS_Report_2008.pdf

Kotler, P., \& Zaltman, G. (1971). Social Marketing: An approach to Planned Social Change. Journal of Marketing, 35, 3-12.

Malinowski, B. (1932). Argonauts of the Western Pacific. London: G. Routledge and Sons.

McPhee, S. J., Jenkins, C. N. H., Wong, C., \& Fordham, D. (1995). Smoking cessation intervention among Vietnamese Americans: a controlled trial. Tobacco Control, 4(1), S16-S24.

Miles, M. B., \& Huberman, A. M. (1984). Qualitative data analysis: A sourcebook of new methods. Thousand Oaks, CA: Sage.

Perry, C. (1995). A Structured Approach to Presenting PhD Theses: Notes for candidates and their supervisors. ANZ Doctoral Consortium, University of Sydney, February.

Petty, R. E., \& Cacioppo, J. T. (1986). Communication and persuasion: Central and peripheral routes to attitude change. New York, Springer-Verlag.

Prochaska, J. O., \& DiClemente, C. C. (1983). Stages and processes of self-change of smoking, Toward an integrative model of change. Journal of Consulting and Clinical Psychology, 51, 390-395.

Redman, S., Spencer, E. A., \& Sanson-Fisher, R. W. (1990). The role of mass media in changing health-related behaviour: a critical appraisal of two models. Health Promotion International, 5, 85-101.

Reiman, J. (1979). Research subjects, political subjects and human subjects. In C. Klockars, \& F. O'Connor (Eds.), Deviance and Decency: the Ethics of Research with Human Subjects (pp. 33-57). Beverly Hills, California: Sage.

Remenyi, D., Williams, B., Money, A., \& Swartz, E. (1998). Doing Research in Business and Management: An Introduction to Process and Method. London: Sage.

Rogers, R. W. (1975). A protection motivation theory of fear appeals and attitude change. The Journal of Psychology, 91, 93-114.

Rosenstock, I. M. (1977). What research in motivation suggests for public health. Journal of Public Health, 50, 295-302.

Smart, N. (1989). The World's Religions (2nd ed.). Cambridge, United Kingdom: Cambridge University Press.

Smart, N. (1996). Dimensions of the Sacred: An Anatomy of the World's Beliefs. University of California Press, Berkeley and Los Angeles, California, Harper Collins Publishers, UK. 
Triandis, H. C. (1977). Interpersonal behavior. Monterey, CA: Brooks/Cole.

Van Esch, P., \& Van Esch, L. (2013). Justification of a Qualitative Methodology to Investigate the Emerging Concept: The Dimensions of Religion as Underpinning Constructs for Mass Media Social Marketing Campaigns. Journal of Business Theory and Practice, 1(2), 214-243.

Van Esch, P., Overton, L., \& Van Esch, L. (2014). Mass Media Social Marketing Campaigns: A review. International Business Research, 7(6), 1-17. http://dx.doi.org/10.5539/ibr.v7n6p1

Van Esch, P., Tsarditze, D., \& Van Esch, L. (2014). Mass Media Social Marketing Campaigns: A practitioners Perspective. International Journal of Marketing Studies, 6(5), 40-51. http://dx.doi.org/10.5539/ijms. v6n5p40

Van Esch, P., Van Esch, L., \& Cowley, J. (2013). The Dimensions of Religion as Underpinning Constructs for Mass Media Social Marketing Campaigns: An Emerging Concept. International Journal of Marketing Studies, 5(1), 96-106. http://dx.doi.org/10.5539/ijms.v5n1p96.

Van Maanen, J. (1998) Different strokes: Qualitative research in the Administrative Science Quarterly from 1956-1996. In J. V. Maanen (Ed.), Qualitative Studies of Organizations (pp. 8-33). Newbury Park, CA: Sage Publications

Veal, A. J. (2005). Business Research Methods: A Managerial Approach (2nd ed.). Pearson Education, Frenchs Forest, Australia.

Woolley, J. E. (2001). Literature review on best practice with mass media. Adelaide: Transport Systems Centre, University of South Australia.

Wundersitz, L. (2011). Best practice in OHSW mass media campaigns, August 2011, (No. (CASR091)). Adelaide: Centre for Automotive Safety Research.

Wundersitz, L., Hiranandani, K., \& Baldock, M. (2009). Annual performance indicators of enforced driver behaviours in South Australia, 2007 (No. (CASR058)). Adelaide: Centre for Automotive Safety Research.

\section{Copyrights}

Copyright for this article is retained by the author(s), with first publication rights granted to the journal.

This is an open-access article distributed under the terms and conditions of the Creative Commons Attribution license (http://creativecommons.org/licenses/by/3.0/). 